CT\&F - Ciencia, Tecnología y Futuro - Vol. 4 Num. 3 Jun. 2011

\title{
ARTIFICIAL LIFT MANAGEMENT RECOMMENDATIONS AND SUGGESTIONS OF BEST PRACTICES
}

\author{
Clemente-Marcelo Hirschfeldt ${ }^{*}$ \\ Oil Production Consulting \& Training, Comodoro Rivadavia, Argentina \\ Universidad Nacional de la Patagonia San Juan Bosco, Comodoro Rivadavia, Argentina \\ e-mail:marcelo@oilproduction.net
}

(Received Apr. 04, 2011 ; Accepted Jun. 07, 2011 )

\section{ABSTRACT}

\begin{abstract}
$\Delta$ rtificial lift systems (ALS) play an important role during the oil field production process. The selection, acquisition, installation, evaluation, monitoring and subsequent inspection of these systems involves different stakeholders, including the companies and different sectors therein. When you add factors such as field location, local culture and the experience of the companies in the area, understanding and analyzing each of the factors is critical not only to maximize the life of a specific ALS, but also to maximize and optimize field production in an efficient, effective manner. Another important factor to consider is the dynamic of developing new oil fields or those affected by different EOR technologies, such as secondary recovery by water injection, where field requirements and conditions change on a continuous basis.
\end{abstract}

This paper presents concepts and recommendations regarding the management of ALS during the productive life of an oil field, contemplating the criteria of selection, acquisition, installation, evaluation and monitoring, as well as the subsequent inspection thereof. The issues analyzed herein also involve concepts related to operating as well as service companies and sectors involved in acquisition, evaluation and monitoring, among others. It also mentions definitions of the roles, functions and competencies required to live up to the challenges posed by these systems.

Keywords: Artificial lift systems, Production engineering, Mature fields.

Citation: Hirschfeldt, C. M. (2011). Artificial lift managemente recommendations and suggestions of best practices. CT\&F Ciencia, Tecnología y Futuro, 4 (3), 7-20.

*To whom correspondence may be addressed 


\title{
RESUMEN
}

\begin{abstract}
T os sistemas de levantamiento artificial (SLA) juegan un rol importante durante el proceso de producción de un campo hidrocarburífero. Su selección, adquisición, instalación, evaluación, monitoreo

y su posterior inspección, involucra a diferentes actores, así también como compañías y diferentes sectores dentro de ellas. Si además le agregamos factores como la ubicación de los campos, la cultura local y la experiencia de las empresas en esas locaciones, el conocimiento y análisis de cada uno de todos estos factores es crítico no solo a la hora de maximizar la vida útil de un SLA específico, sino también a la hora de maximizar y optimizar la producción de un campo de forma efectiva y eficiente. Otro factor importante a ser considerado es la dinámica que presenta el desarrollo de nuevos campos hidrocarburíferos o aquellos que estén afectados a distintas tecnologías de EOR como los de recuperación secundaria por inyección de agua, donde los requerimientos y las condiciones de los campos cambian en forma continua. El siguiente trabajo presentará algunos de los conceptos y recomendaciones relacionadas a la gestión de los sistemas de levantamiento artificial durante la vida productiva de un campo hidrocarburífero, contemplando los criterios de selección, adquisición, instalación, evaluación y monitoreo, así como su posterior inspección. Estos puntos analizados también involucrarán conceptos que estarán relacionados tanto a las empresas operadoras, como las empresas de servicio, y a sectores relacionados a la adquisición, evaluación y monitoreo, entre otros puntos. Así mismo se mencionarán algunas definiciones de roles, funciones y competencias a ser requeridas, para poder hacerle frente a los desafíos que estos sistemas presentan.
\end{abstract}

Palabras claves: Sistemas de levantamiento artificial, Ingeniería de producción, Campos maduros.

\section{RESUMO}

O s sistemas de levantamento artificial (SLA) cumprem um papel importante durante o processo de produção de um campo Hidrocarbonífero. Sua seleção, aquisição, instalação, avaliação, monitoramento e sua posterior inspeção envolvem diferentes atores, assim como companhias e diferentes setores dentro delas. Se, além disso, acrescentamos fatores como a localização dos campos, a cultura local e a experiência das empresas nesses lugares, o conhecimento e a análise de cada um de todos estes fatores é crítica não apenas no momento de maximizar a vida útil de um SLA específico, mas também no momento de maximizar e otimizar a produção de um campo de forma efetiva e eficiente. Outro fator importante que deve ser considerado é a dinâmica que apresenta o desenvolvimento de novos campos hidrocarboníferos ou daqueles que estiverem afetados a distintas tecnologias de EOR como os de recuperação secundária por injeção de água, onde as necessidades e as condições dos campos mudarem de forma contínua. $\bigcirc$ seguinte trabalho apresentará alguns dos conceitos e das recomendações relacionadas à gestão dos sistemas de levantamento artificial durante a vida produtiva de um campo hidrocarbonífero, contemplando os critérios de seleção, aquisição, instalação, avaliação e monitoramento, assim como sua posterior inspeção. Estes pontos analisados também envolverão conceitos que estarão relacionados tanto com as empresas operadoras, como com as empresas de serviço, e com setores relacionados com a aquisição, avaliação e monitoramento, entre outros pontos. Também serão mencionadas algumas definições de papéis, funções e competências necessárias, para poder fazer frente aos desafios que estes sistemas apresentam.

Palavras chaves: Sistemas de evantamento artificial, Engenharia de produção, Campos maduros. 


\section{INTRODUCTION}

\section{ALS Management Cycle}

Developing an oil field using Artificial Lift Systems (ALS) involves different stakeholders and activities that are part of the comprehensive management cycle of said systems. Identifying each of the stages and the people who take part in the processes is fundamental to be able to optimize existing procedures or implement a comprehensive medium and long-term management strategy.

The system illustrated in Figure 1 can be considered a management cycle during the implementation and operation of ALS, and can serve as a guide to be able to analyze the different aspects involved in the process.

The cycle can start out with the selection of one or more ALS alternatives based on the analysis of information on the reservoirs to be produced, well data in terms of the construction, and other aspects that will be discussed throughout this paper. Based on this analysis and once the best method(s) have been selected, we go on to the stage of well acquisition, installation and operation, which closes one of the first sub-cycles in a comprehensive management system (Hirschfeldt, 2010).

Once the well has been started up, the monitoring and control of its operating variables is essential not only to guarantee the optimum operation of the ALS within the established parameters, but also to maximize reservoir production. Continuous analysis may generate the need to work on the system in operation, either based on surface action (changes in systems or other operating condition) as well as downhole action, either by replacing elements or the ALS for another in order to meet development objectives.

Another situation that may arise is the failure of one of the components of the installed system, which, based on the analysis and evaluation thereof, should provide information for decision-making when it comes to the design of future facilities. In other cases, when the mechanical limit of the ALS has been exceeded, you may have to redefine the development strategy of an oil field as regards the implementation of secondary recovery projects, geometry and well depth, etc.
During this management cycle, interdisciplinary work and the participation of the different companies involved is a common factor in these processes. These factors have been listed and classified in Table 1 below.

\section{ALS ANALYSIS, SELECTION AND DESIGN}

\section{Selection Criteria}

Although there has been discussion regarding ALS selection criteria over the last 40 years as the industry has involved, it is important to review some of the most important criteria and considerations when it comes to selecting an ALS (Clegg, Bucaram \& Hein, 1993). The selection criteria include but are not limited to the following:

- Based on the mechanical limit.

- Based on advantages and disadvantages.

- Selection through expert programs.

- Selection by comparison of Net Present Value (NPV).

Based on the experience of companies using the different ALS, the conjunction of these methodologies is common practice, so more than one methodology is usually used. Table 2 provides a summary of the considerations that encompass the criteria listed above.

\section{Processes and Participants Involved in ALS Selection and Design}

The selection process should include a vision of the present as well as the future development of the field, without disregarding past experiences. It should also consider multidisciplinary efforts, mainly in the fields that are subjected to sustained, continuous development. This process definitely begins with the planning of drilling and termination, and the development strategy of the wells in question (Clegg et al., 1993).

For instance, when a well is designed (diameter and route), many aspects should be shared beforehand with those who will play a direct role in selecting an artificial lift system, because it can limit the type of systems that can be used or the maximum extraction capacity there of, and therefore affect the development of the reservoir. 


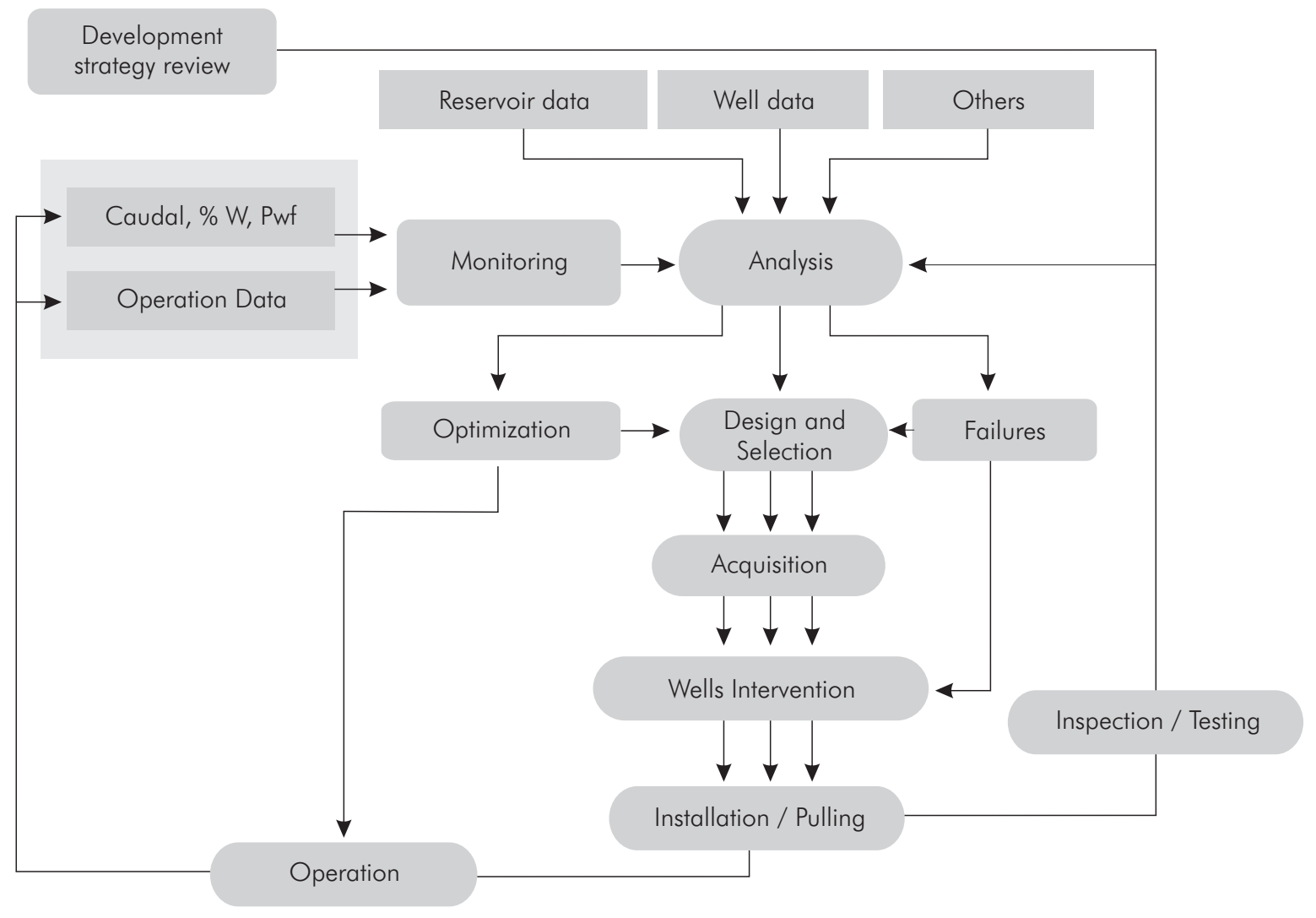

Figure 1. ALS Management Cycle

In addition, the reservoir department should provide information on the production forecast based on the implementation of a secondary recovery project or other development plan.

The minimum technical competencies required by those who will participate directly in selection, design and analysis include:

- Performance analysis of the reservoir and surrounding areas (PI - Productivity Index and formation damage are parameters that affect flow performance in reservoirs).

- Physical chemical properties of the fluids produced.

- Concepts of fluid dynamics, mechanics and electricity.
- Principle of operation and limits of the different ALS.

\section{Mechanical Limit as an ALS Selection Criterion}

During the selection and design process, one of the most important factors to be taken into consideration is a system's capacity to transfer power from the unit itself to the pump. Therefore, casing diameter becomes one of the most important border conditions because it restricts not only tubing diameter, but also other elements such as sucker rods or centrifugal pump shafts. Figure 2 illustrates power transfer in classic artificial lift systems (Hirschfeldt \& Ruiz, 2009).

Dealing with the unpredictability of the failure of the elements of ALS that exceed said mechanical limit is an everyday task for Production Engineering Departments. 
Table 1. Processes and Participants Involved in ALS Management

\begin{tabular}{|ccc|}
\hline & & \\
& & \\
PROCESSES & OPERATOR & SERVICES \\
Analysis & Production engineer & Commercialization \\
\hline Selection & Production operations & Application engineering \\
\hline Acquisition & Reservoirs & Sales \\
\hline Installation/pulling & Drilling & \\
\hline Inspection & Supplies & \\
\hline Operation & Contracts & \\
\hline Monitoring & & \\
\hline
\end{tabular}

Table 2. Summary of considerations contemplated in ALS selection criteria

\begin{tabular}{|c|c|c|c|}
\hline RESERVOIR & WELL & OTHERS & ECONOMIC \\
\hline Productivity (Static Pressure Caudal vs Pwf) & Location (on-shore - off-shore) & Flexibility & Initial investment \\
\hline Reservations involved & Geometry & Energy & Operating cost \\
\hline $\begin{array}{c}\text { Fluid type (\% of phases, viscosity, solid } \\
\text { content, fluid aggressiveness) }\end{array}$ & Diameter & Products and services & Services cost \\
\hline GOR & & Availability & Re-sale \\
\hline \multirow[t]{3}{*}{ Bottom temperature } & Completion & Previous experience & \\
\hline & Depth & Surface disturbance & \\
\hline & Temperature & Visual impact & \\
\hline
\end{tabular}

Although some of the recommended procedures in this area are mentioned throughout this paper, it can be said that failure analysis and subsurface equipment testing following extraction are fundamental when it comes to making decisions regarding new designs or repairs. In addition, if the analysis of the root cause of said failures concludes that the mechanical limit of the ALS has been reached, a change in production strategy is required.

The following is an example of how the mechanical limit of an ALS can condition the development of an oil field, where oil production is the result of water injection as a secondary recovery method:

- The project considers a gradual increase in water injection volumes in accordance with oil pro- duction decline (normal situation in Sec. Rec. projects).

- The increase in water injection triggers an increase in total fluid per well and, therefore, in the power transmitted from the motor to the pump, which can cause the sucker rods (mechanical or progressive cavity pumping) or the centrifugal pump shafts to exceed maximum capacity.

- This situation can lead to the reconsideration of a restriction in the water injection volume or other distribution, because the optimum development of these projects is associated with the right balance between Injection and Production. 


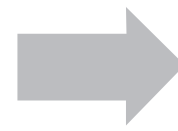

ENERGY

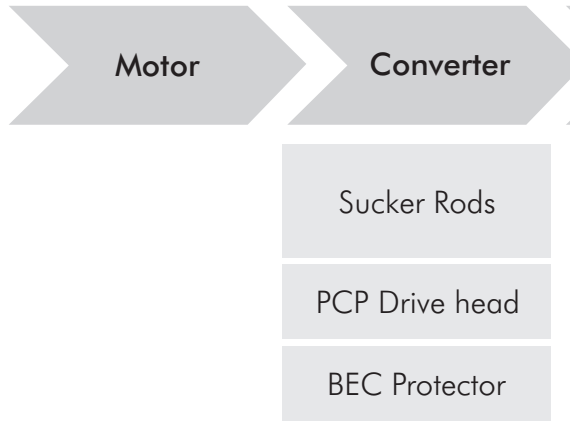

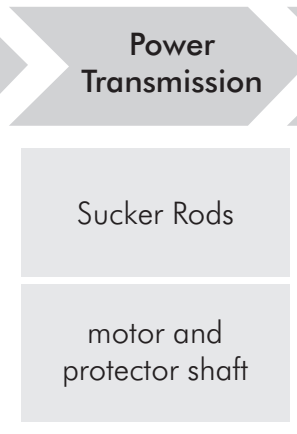

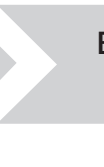

Bottom Pump

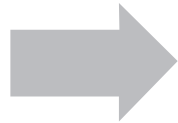

FLOWRATE AND PRESSURE

Figure 2. Power transfer in artificial lift systems

\section{ALS PERFORMANCE EVALUATION}

The analysis requires the proper logging of operating variables, in which their quality is fundamental in order to make the right decisions. Regardless of whether the variables are taken manually or automatically (sensors / recorders), their analysis and integration is important in order to be able to conduct a performance analysis for decision-making purposes. These variables include:

\section{Production Controls}

The measurement of the volume produced by the different phases (oil, water and gas) is fundamental when it comes to evaluating not only well potential but also the performance of the production system itself. The first question we have to ask ourselves is "What do we need?... ¿a large number of production controls each month to meet the quantitative objectives ..or few quality controls that will enable us to make decisions that will add value and help optimize the fields?

\section{Fluid Levels (Dynamic Pressures)}

Monitoring dynamic fluid level (associated with the reservoir's dynamic pressure) should be a part of essential monitoring routines.

They can be acquired by down hole sensors (measuring suction pressure) or at the surface using manual echo-sounders.

Due to the importance of these measurements, along with production volume to determine reservoir poten- tial (volume vs. dynamic pressure), production control and level measurements should be in line with similar development conditions for the best approximation to determine the extractive potential of production wells.

\section{Operating Parameters}

- Electric current (fundamental in Electric Submersible).

- Loads in surface units (PCP and Sucker Rod Pumping).

- Loads in rods (PCP and Sucker Rod Pumping).

- Pumping Speed: RPM (Revolutions per minute), SPM (Strokes per minute), Hz, working stroke, etc.

- Downhole vibrations (ESP).

- Wellhead pressure.

- Downhole temperatures (Motor temperature, downhole equipment temperature).

The following are examples of variable monitoring in different artificial lift systems: Figure 3, 4 and 5.

\section{INSPECTION, FAILURE ANALYSIS AND REUSE OF SUBSURFACE ELEMENTS}

After extracting Subsurface elements used in ALS from the well, inspection should be a part of the work routines at the companies using the different systems. 
Operating Speed vs. Suction Pressure

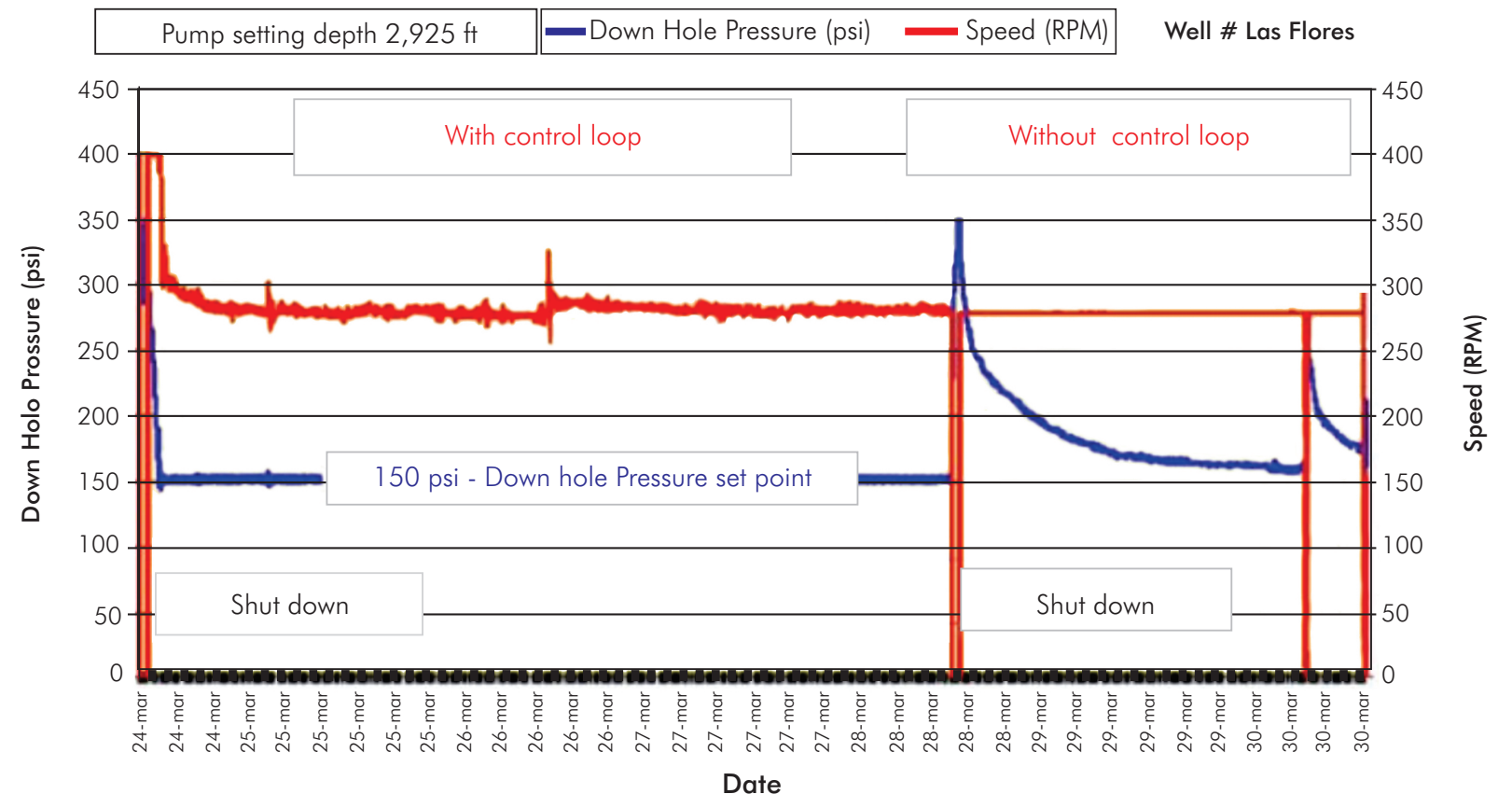

Figure 3. On line revolution speed log (RPM) and suction pressure in BCP based on a control loop governed by a frequency inverter (Hirschfeldt, 2005)
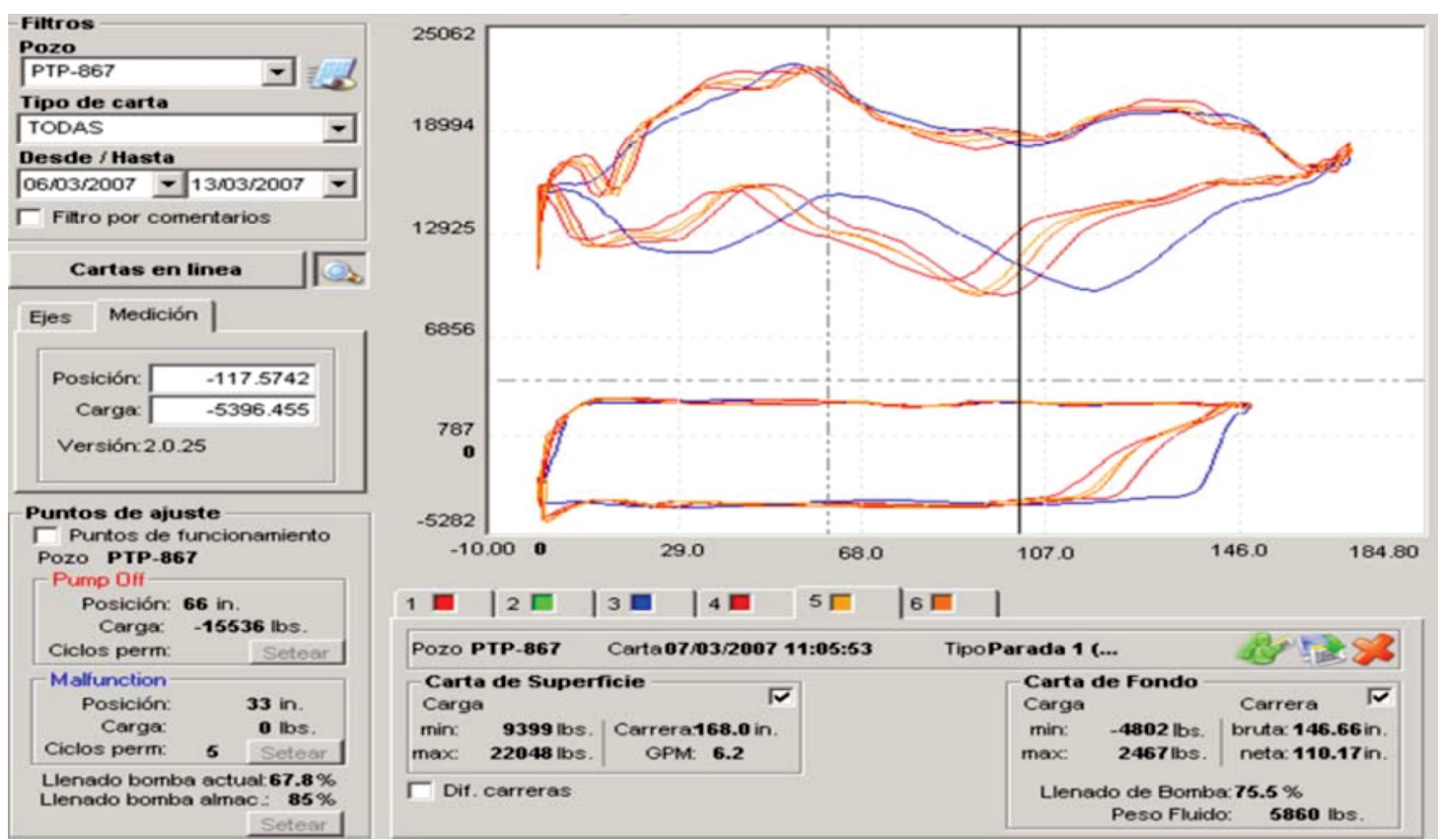

Figure 4. Dynamometric log in wells with mechanical pumping based on telemonitoring systems 


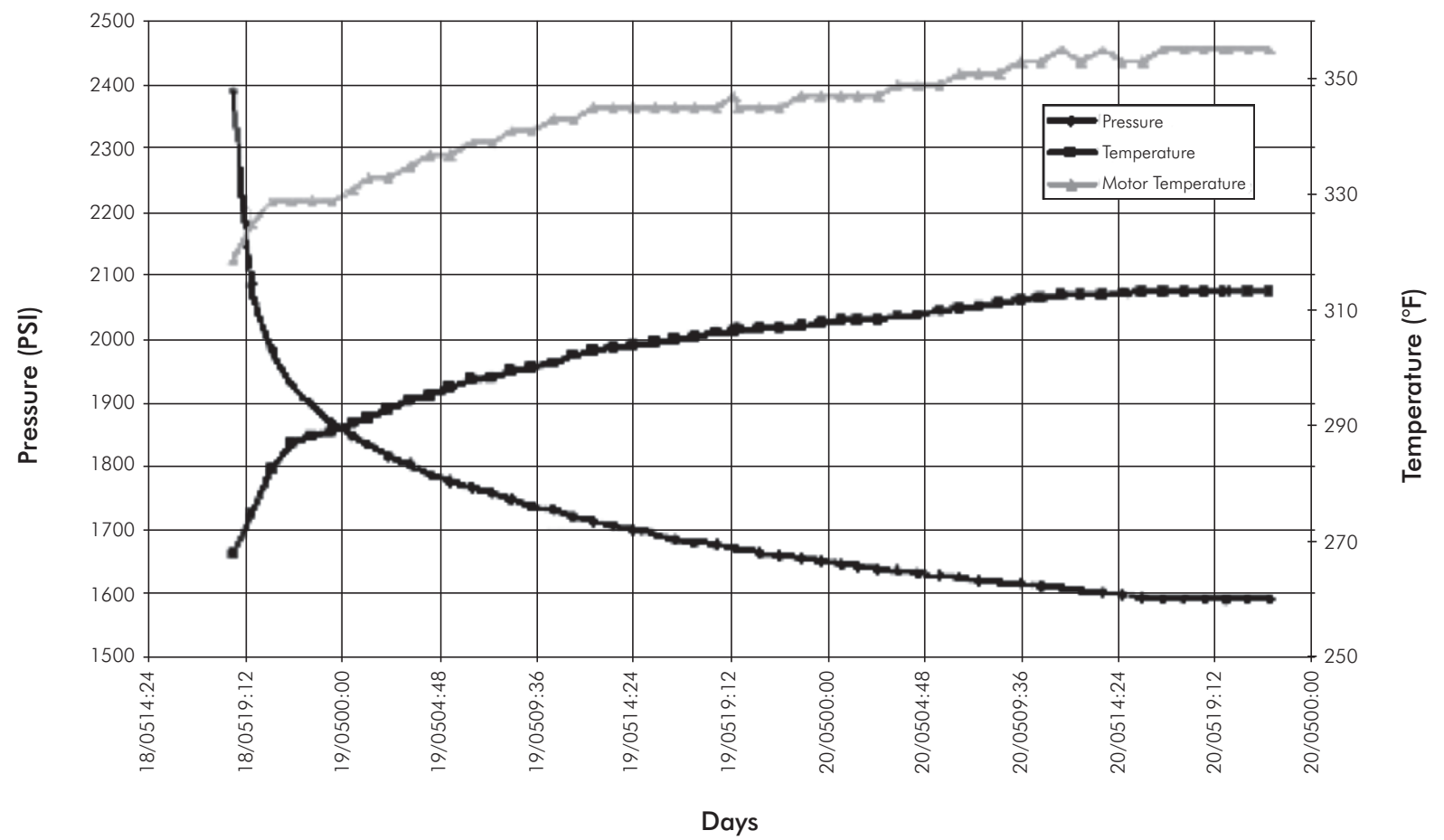

Figure 5. Log of motor temperature, downhole temperature and suction pressure in a ESP system

These processes not only allow you to evaluate the performance of the equipment extracted, but also enable more in-depth failure analysis and the reuse of subsoil elements if they are within certain parameters.

As regards the reuse of materials, this does not mean elements deficient in quality are going to be installed in the well, because you have to bear in mind that one of our objectives is to maximize the life cycle of production wells. Proper classification of materials based on the traceability of their history will help us save a great deal on production costs.

"In mature fields where the production cost increases significantly, inspection and the reuse of subsoil elements is fundamental in order to maintain the profitability of many fields, but in order to do so, the operating company and the professionals in charge have to become directly involved in the process."

\section{Inspection of Subsurface Equipment}

The following is a description of examples associated with inspection and the performance analysis of subsoil equipment extracted from the well of the main ALS:

\section{Progressive Cavity Pumping (PCP)}

- Visual and dimensional rotor inspection. Chrome plating of those that lose only the external cover.

- Visual and dimensional stator inspection.

- Performance testing in test bench, logging of the volume, power and torque required for different pressures and RPM.

- Identification of deformation cycles accumulated by stator elastomer before testing as criteria for acceptance and disposal (Hirschfeldt, 2001) (Figure 6 and 7).

\section{Electric Submercible Pump (ESP)}

- Pump testing in test bench (measurement of flow and power consumed).

- Disassembly of pumps for dimensional control, eliminate scaling or plugging due to heavy crude during the different stages and subsequent reuse of the elements. 
- Motor testing and repair: Drying of winding, condition of bearings, dielectric state of winding, etc.

- Testing of protective seals: dynamic testing, logging power consumed based on axial charges.

- Dielectric testing for power cable (API 11S) (Figure 8).

\section{Sucker Rod Pumping}

- Disassembly of pumps inspecting each of the elements: valves (seat and ball), barrel, anchor.

- Hydraulic testing (API 11AR).

\section{Failure Analysis and Evaluation}

Subsurface Failures and Their Impact on ALS Implementation

As regards ALS management, both failure analysis and statistical monitoring and logging are important when it comes to providing feedback for the decision- making circuit. It is a well-known fact that a recurring failure in a key ALS element not only causes production losses, but also gives rise to costs associated with pulling services to replace elements of the installed system.

In turn, depending on the type of location/environment where the system is installed (jungle, sea, remote fields, etc.), not only will the associated costs be higher, but at times, it cannot be accessed with service to extract the damaged element from the well in time and form.

All the above translates into the reliability of the equipment that many times is not only associated with installing expensive equipment, but also knowing about previous experiences based on the historic log of failures and their respective root cause analyses.

\section{Key Performance Indicators (KPI)}

The use of performance indicators is important when it comes to making decisions or monitoring the evolution of a field as regards failures in ALS elements. Classic indicators include:
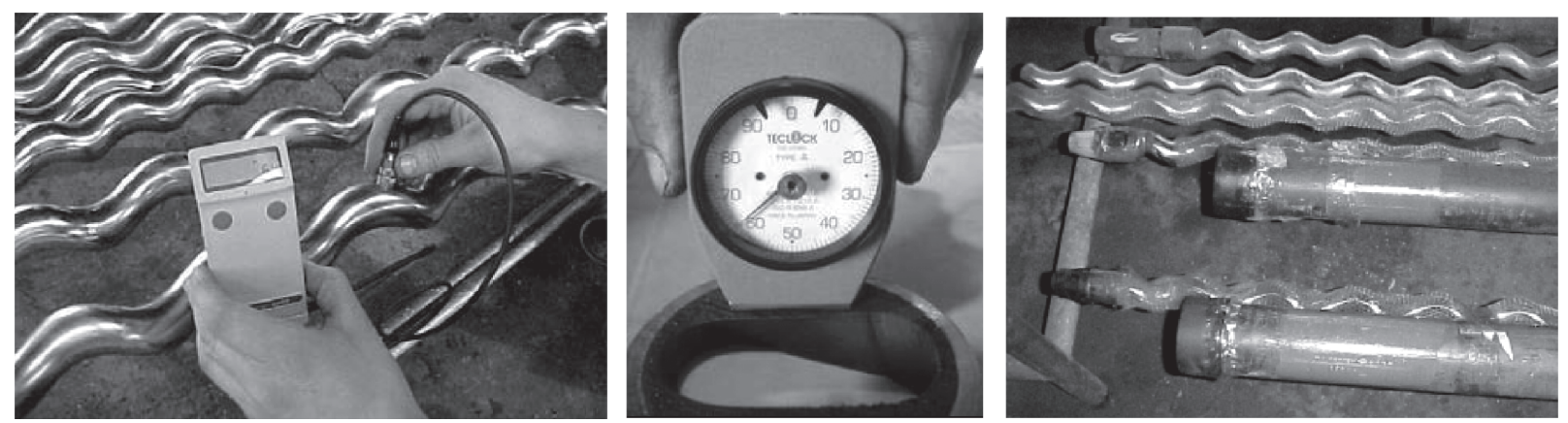

Figure 6. "In-House" inspection and Recovery procedures for PCP. Diadema Field (CAPSA). Patagonia Argentina (Year 2001) (Hirschfeldt, 2001; Hirschfeldt, 2006; Hirschfeldt, 2003)
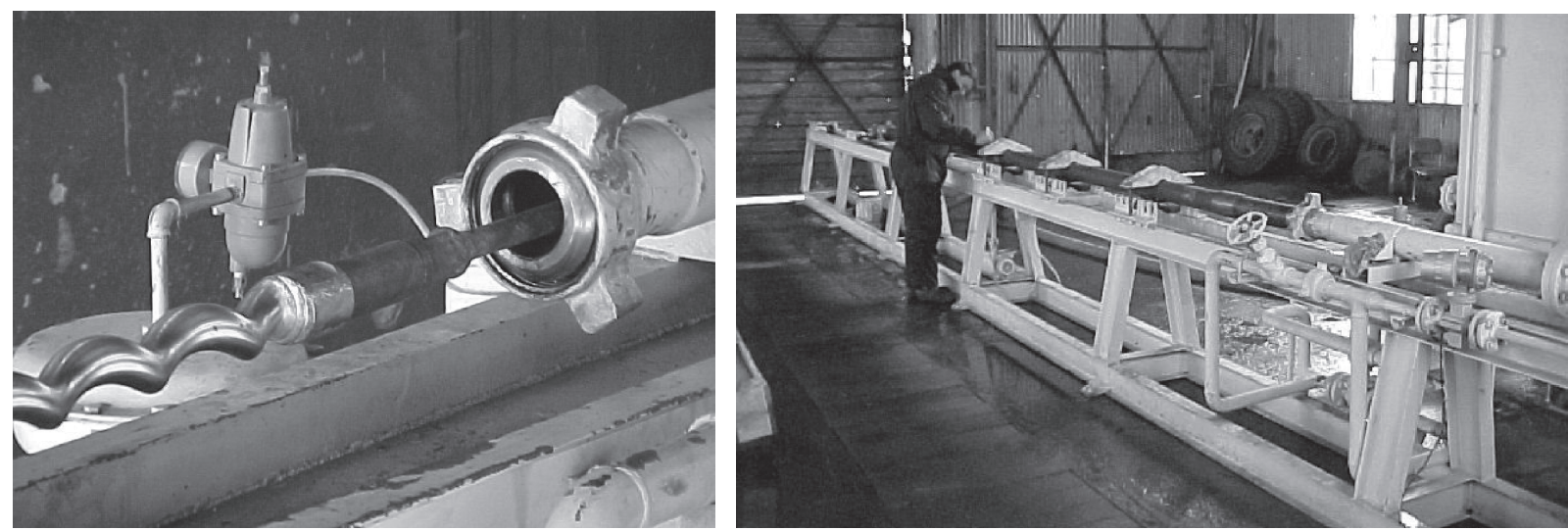

Figure 7. "In-House" testing of PCP. Diadema Field (CAPSA). Patagonia Argentina (Year 2001) (Hirschfeldt, 2001; Hirschfeldt, 2006; Hirschfeldt, 2003) 

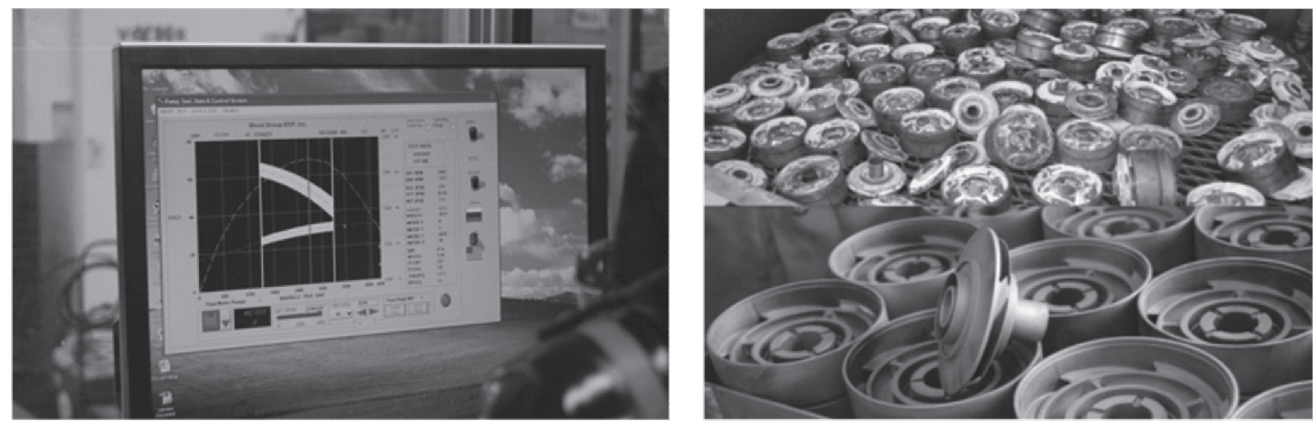

Figure 8. Testing of centrifugal pumps and inspection of ESP equipment stages in service company workshops (WoodGroup ESP. Colombia)

\section{API (Annual Pulling Index)}

This indicator can be logged month by month and it allows you to forecast the number of failures wells will have on average in one year. It is expressed in Interventions / well / year. For instance, if we have a population of 100 production wells and, in one month, we have 5 interventions with pulling equipment due to failures in the wells, we have:

$I P A=\left(N^{o}\right.$ of interventions $) /($ Running Productive wells $) \times$ 12 months $=5 / 100 \times 12=0$, 6interventions $/$ wellyear

This means each well would fail 0,6 times per year, or that the life cycle of a well is approximately 1,6 years.

This simple indicator can be applied to monitor failures per well, per field, per type of ALS, per system element (rods, pump, tubing, etc.) or per causes originating the failures.

\section{APPLICATION OF ALS BASED ON THE PRODUCTION HISTORY OF WELLS}

\section{Variation in production potential}

During the life of an oil well, its production potential will vary depending on the type of drain system and/or external power input such as secondary recovery projects. This is an everyday situation in most oil fields in the world and the following are several possible scenarios:

\section{Fields with naturally flowing wells}

Kickoff with continuous Gas Lift in flowing wells with high productivity / high gas: liquid ratio and availability as regards injection gas pressure and volume.

- As well productivity begins to decline (power loss), more external power has to be supplied.

- As this demand increases, the system is inefficient at times from the energy standpoint as well as due to the lack of gas compression capacity (high costs, maintenance, gas shortage, etc.).

- Due to the decrease in the gas: liquid ratio (increase in liquid column density), depending on the liquid volume to be extracted, it may be possible to migrate to an intermittent $\mathrm{BN}$ system, plunger lift, mechanical pumping, or perhaps an electric centrifugal pumping system (ESP) depending on production potential.

\section{Oversaturated Fields in the Process of Decline}

Where depending on reservoir pressure and petro physical parameters, the decline can take place over several years' time (between 5 and 10 years), or even less, such as the case of reservoirs with very low permeability with sudden declines over the first 6 months of development:

- The ESP installation is the first choice due to the mechanical pumping limitations for the assumed conditions of depth and volume.

- As well production begins to decline (decrease in the potential fluid volume), the mechanical pumping system may be the alternative to cover a wide range of volumes during the remaining productive life. 


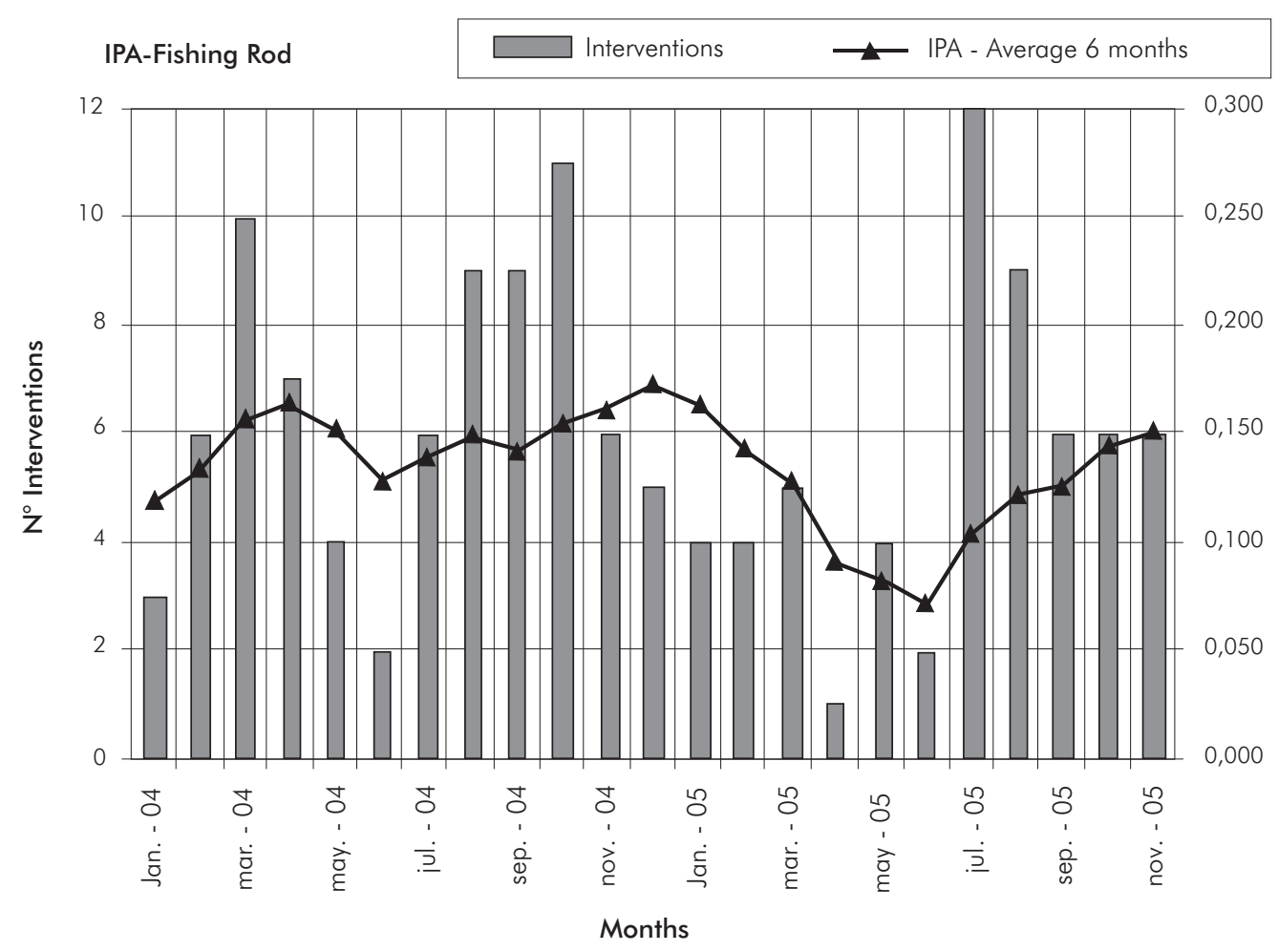

Figure 9. Example of monitoring the well intervention index as a performance indicator in the life cycle of wells with ALS

Mature fields affected by a secondary recovery project

Are another common scenario during the revitalization of mature fields.

- During its history of decline (previous case), a well can end its productive life cycle with a mechanical pumping system with a low production rate and smalldiameter pumps.

- When water injection starts in an adjacent secondary recovery project, productivity (associated with the increase in reservoir pressure) will rise, so depending on the mechanical limit and flexibility of the current system, changing over to other systems such as progressive cavity (PCP) or electric centrifugal pumping (ECP) is a step to be taken into consideration.

\section{Evolution of the Application of ALS}

Based on the productive history of the oil fields, and as its power is modified, different ALS can be used to adapt to their requirements. Figure 10 illustrates the productive history of a well and the possible ALS changes throughout the life thereof.

\section{References - Figure 10}

1. Mechanical Pumping: At a low extraction rate as total fluid production declines.

2. Progressive Cavity Pumping (PCP): The flexibility of this system makes changes in extraction rate fast and simple, as the output of fluid from the reservoir increases.

3. Electric Centrifugal Pumping (ECP): The high RPM of ECP generates problems of wear in production tubing and rods, and the elastomer becomes brittle. Since new perforations are opened at a deeper level to expand the secondary recovery project, the ECP system allows the extraction of these volumes at said depths, perhaps exceeding the mechanical limit of the sucker rods of a PCP system.

"A production well may require more than one type of Artificial Lift System during its productive life (Hirschfeldt, Distel \& Martínez, 2007)." 


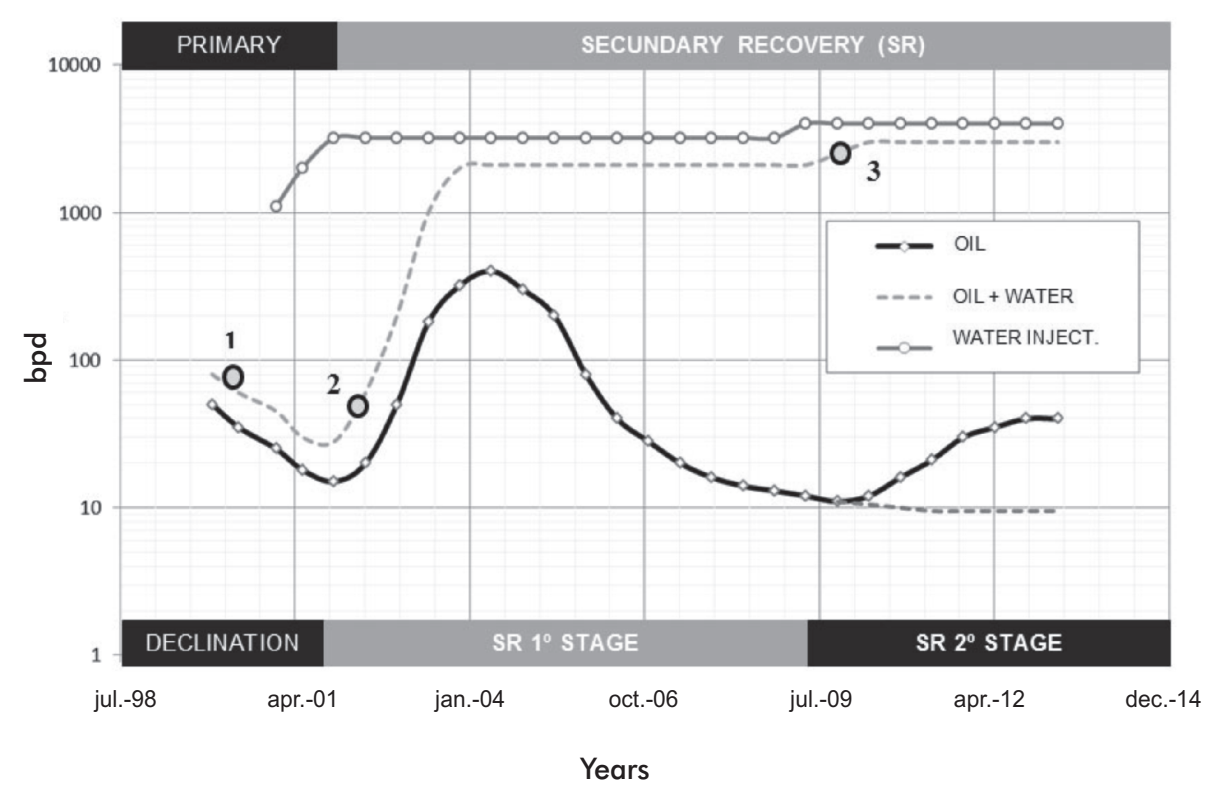

Figure 10. Evolution of the application of an ALS throughout the productive life of a well

\section{INTEGRAL MANAGEMENT OF ALS}

As we have gone over throughout this article, comprehensive ALS management in an oil field is associated with different stages that involve stakeholders, including people, sectors and companies.

The different management models depend on the ALS experience of operating companies and their professionals. The following are two possible scenarios that represent cases existing in the Latin American region.

\section{Case A -Oil Field Operators with Experience in the application and widespread use of ALS}

They can be in condition to evaluate and select the products offered on the market as well as the service companies associated with said products (Figure 11).

Depending on the size of these companies, many time acquisition takes place by alliance (between operators and services), which also include maintenance, inspection, monitoring and engineering services, among others. The Production Engineers of the operating companies also play an active role in testing equipment, evaluating performance and analyzing failures, at either their own laboratories or those of the service companies. This model is usually associated with alliances or frame- work agreements between operators and product/ service suppliers, but they are generally the result of the knowledge of the needs of the operator, supported by the experience of a specific service company.

\section{Case B -Operators with out experience in ALS ma- nagement}

Design, selection and installation are almost entirely delegated in the companies that supply these products, with practically minimal participation of the oil field operators in this stage (Figure 12).

As regards the acquisition of the equipment related to each ALS, it is often based on framework agreements or alliances where the service companies design, provide and operate the ALS in which the equipment for each well is leased in many cases.

This method would be a good start during the learning curve of operators, because it is important to depend on the experience of service companies in this regard. But in many cases, the practically full delegation of ALS management disregards the responsibilities of those who should be carrying out the process, such as the areas of Production Engineering or Development, because not only is optimum reservoir development at stake, but also the costs associated with the development of the fields (costs of materials, services, power, etc.). 


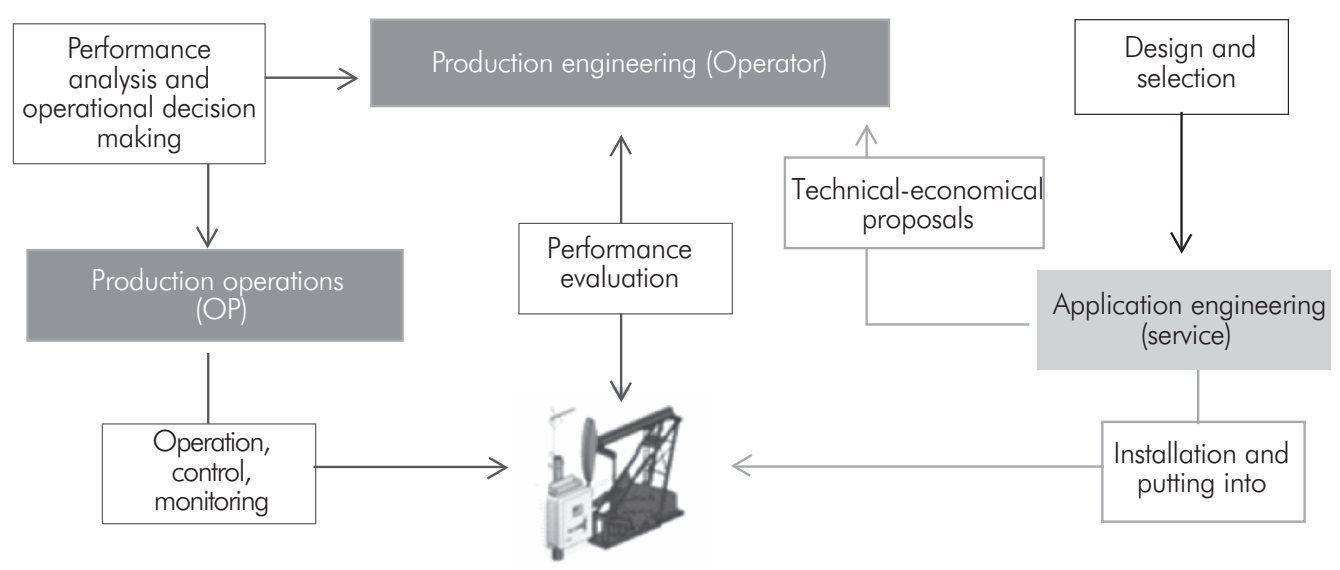

Figura 11. Management system of companies operating oil fields with experience in ALS application

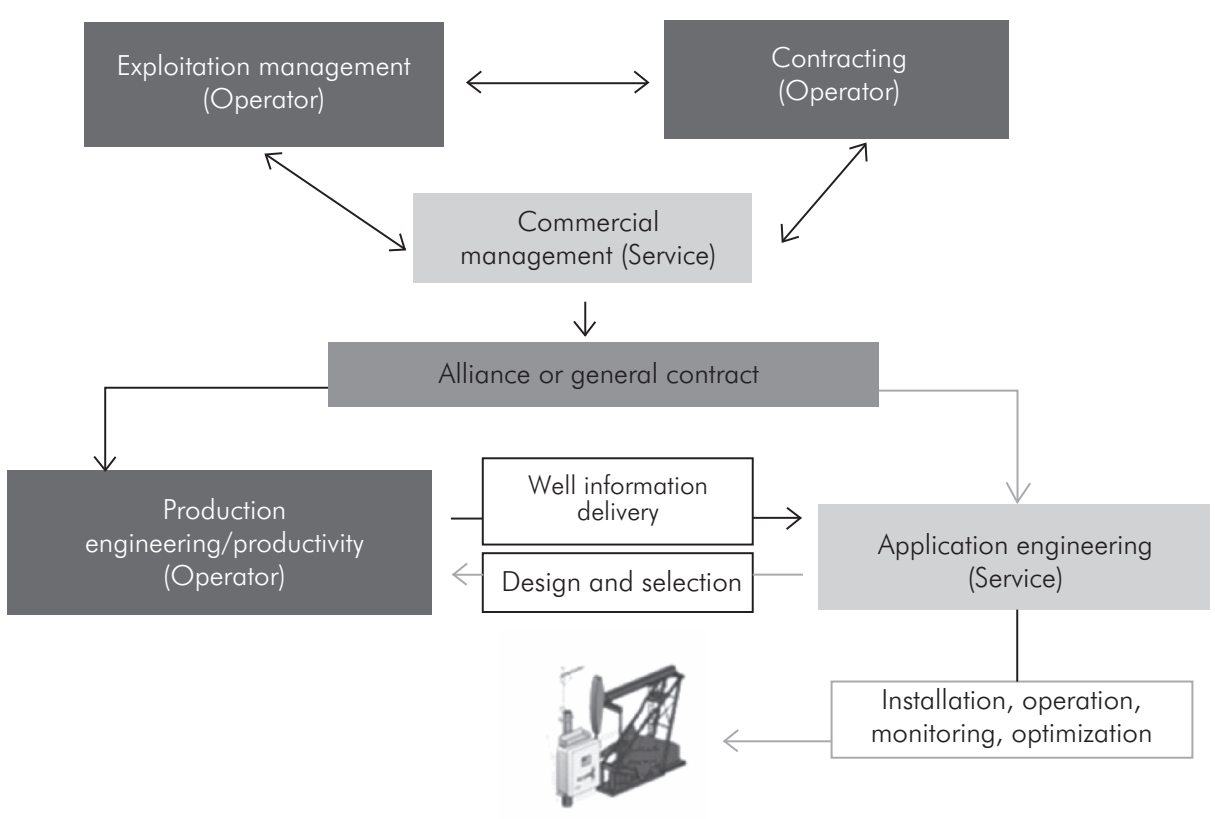

Figure 12. Operators with Scarce Experience in the management and widespread use of ALS

Another possible disadvantage of these models is that they are usually static and Production Engineers find that the only options to choose an ALS are delimited by a framework agreement. This situation may prevent people from choosing alternatives that actually match the needs of the well or field to be developed.

"It is important to select and acquire ALS equipment based on the present and future needs of my wells and not choose candidate wells once the ALS have been acquired in a widespread manner."

In order to increase the involvement of operators in this management process (Case A), you should start out with comprehensive training for the professionals related to the activity to get to know the types of ALS, their principles of operation, mechanical limits and maintenance requirements, among other important 
aspects. In addition, benchmarking with operators that have more experience is another valid alternative, because you can learn from those who have already gone down the same path on the matter.

\section{CONCLUSIONS}

Although the strategies to develop oil fields may vary a great deal based on their maturity or the corporate philosophy regarding the development of a field, ALS management should be taken on with a strategic, integrated vision in accordance with the development of a field.

It is obvious that the increasing number of production wells that require an ALS in a field make it fundamental to implement management systems or work methodologies as regards analysis, selection, design, operation and optimization, not only due to the need to maximum oil production, but also due to the high economic impact that the products and services associated with the ALS have on production costs.

Regardless of the working methodology implemented, the starting point is an understanding of the theoretic and practical/operative concepts related to the principles of operation and limits of the ALS.

In addition, the firm commitment of those who have to deal with these issues will be required, from development management units to operating sectors, mainly in the fields where there is no culture associated with the use of ALS and where classic systems can turn into new technologies for these areas due to their scarce use.
Clegg, J.D., Bucaram, S.M. \& Hein, N.W. (1993). Recommendations and Comparisons for Selecting Artificial Lift Methods. J. Petrol. Tech. 45 (12), 1128-1131, 1163-1167.

Hirschfeldt, C. M. (2001). PC Pump in Diadema Oilfield. San Jorge Basin. Argentina. SPE Progressing Cavity Pumps Workshop, Puerto la Cruz, Venezuela.

Hirschfeldt, C. M. (2003). Manifestación del Fenómeno de Histeresis En Pcpump En Yac. Diadema. II Congreso de Hidrocarburos IAPG. Buenos Aires, Argentina.

Hirschfeldt, C. M. (2005). Pcpump Automation in Cerro Dragon Oilfield. SPE Progressing Cavity Pumps ATW, Bariloche, Argentina.

Hirschfeldt, C. M. (2006). Artificial Lift Experience in Mature Fields - Case Study Golfo San Jorge Basin. Artificial Lift Conferences, Jakarta, Indonesia.

Hirschfeldt, C. M. (2010). Artificial Lift Management. SPE Applied Technology Workshop-Artificial Lift System, Cancún. Mexico.

Hirschfeldt, C. M., Distel, F. \& Martínez, P. (2007). ArtificialLift Systems Overview and Evolution in a Mature Basin: Case Study of Golfo San Jorge . SPE Latin American and Caribbean Petroleum Engineering Conference held in Buenos Aires, Argentina. SPE 108054.

Hirschfeldt, C. M. \& Ruiz, R. (2009). Selection Criteria for Artificial Lift System Based on the Mechanical Limits: Case Study of Golfo San Jorge Basin SPE Annual Technical Conference and Exhibition held in New Orleans, Louisiana, USA. SPE 124737.

\section{REFERENCES}

API 11S. Recommended Practice for the Operation, Maintenance and Troubleshooting of Electric Submersible Pump Installations.

API 11AR. Recommended Practice for Care and Use of Subsurface Pumps. 